\title{
9. FIRST MEASUREMENTS OF THE MAGNETIC FIELD WITHIN THE OCEAN CRUST: DEEP SEA DRILLING PROJECT LEGS 68 AND 691
}

\author{
V. N. Ponomarev and V. L. Nekhoroshkov, Institute of Geophysics, Pervomayskaya 91, Sverdlovsk 620049, U.S.S.R.
}

\begin{abstract}
A downhole magnetometer was deployed within the ocean crust for the first time in holes drilled on the south flank of the Costa Rica Rift during Deep Sea Drilling Project Legs 68 and 69. The holes in question were Holes 501, 504B, and 505B. The magnetometer was a three-component fluxgate and measured magnetic susceptibility, the vertical field, and two horizontal components of the field oriented relative to the dip of the drill holes. Hole 505B was too near the vertical for the horizontal orientation to be stable.

In all holes, the anomalous field was far too intense to have been caused by induced magnetization. Most of the field is the effect of remanent magnetization. The direction of the magnetization vector changes with increasing depth in the holes, but the effect of secular field variation is difficult to distinguish from that of tectonic rotation. Large systematic deviations that may herald a reversal appear in the in-hole magnetic anomalous field vector near a depth of 200 meters in Hole 504B, but measurements were not continued in the lower part of the hole. Zones of low anomalous field intensity in Hole 504B seem to correspond to zones of brecciation.
\end{abstract}

\section{INTRODUCTION}

The world's first oceanic downhole magnetic measurements were made in July 1979 on Leg 68 of the Deep Sea Drilling Project in Hole 501, which is on the Costa Rica Rift in the eastern Pacific Ocean (Fig. 1). This was followed during Leg 69 by measurements in Holes 504B and 505B. The measurements were made to provide information about the in situ physical state of the hole, especially in regions where recovery was poor, and to provide oriented magnetic information to supplement that obtained from the minicores, which give inclination only. The latter information was particularly important in the Costa Rica Rift, where the magnetic latitude is so low that reversals of inclination can easily take place during normal secular variation of the field (Harrison and Watkins, 1978). The use of downhole magnetometers is especially important where holes are in very low magnetic latitudes, as they were here.

Before we present the results from Legs 68 and 69, we describe the instrument and outline the procedures followed to interpret the measurements from this type of instrument. Our method of interpretation is based on experience with downhole magnetometry in the Soviet Union, where it has been used extensively since 1959 to determine the position and shape of magnetized bodies in drill holes, particularly during prospecting for magnetic ores.

\section{INSTRUMENT DESCRIPTION}

The instrument used on Legs 68 and 69 was a KCM65 (complex borehole magnetometer 65), which was developed by the Institute of Geophysics of the Urals Scientific Center, Academy of Sciences, U.S.S.R. The in-

\footnotetext{
${ }^{1}$ Cann, J. R., Langseth, M. G., Honnorez, J., Von Herzen, R. P., White, S. M., et al., Init Repts. DSDP, 69: Washington (U.S. Govt. Printing Office).
}

strument uses fluxgate sensors to measure magnetic susceptibility and three components of the in-hole magnetic field. The device is intended for the investigation of drill holes of depths up to 10,000 meters. It has two parts, which may be used separately or together: a field detector unit, which has a diameter of $65 \mathrm{~mm}$ and a length of 1.7 meters; and a magnetic susceptibility unit, which has a diameter of $68 \mathrm{~mm}$ and a length of 1.2 meters. The field detector unit is a single-element fluxgate magnetometer with three detectors that are oriented by gravity. One detector is always vertical and measures $\vec{Z}$. A second is horizontal and measures the field in the direction of the dip of the hole, $\vec{H}_{x}$ (the horizontal direction in the plane that contains both a vertical line and the axis of the drill hole). The third detector is also horizontal and is at right angles to the other two. The detectors are oriented by gimbals. This system is shown in Figure 2, where it is compared with an alternative and more widespread system in which one of the detectors is aligned parallel to the axis of the hole.

For the orientation to be effective, the axis of the hole must not be too near the vertical, because the directions corresponding to $\vec{H}_{x}$ and $\vec{H}_{y}$ will not be established clearly enough and large fluctuations will result in the observations of $\vec{H}_{x}$ and $\vec{H}_{y}$ because of the rotation of the gimballed system about the vertical. This sets a lower limit on the deviation of the hole from the vertical of 2 to $3^{\circ}$. The maximum acceptable deviation from the vertical is $30^{\circ}$. Because of the gimballing, better results are obtained with greater deviations of the hole from the vertical, and these are also more convenient for interpretation. The field detectors have an average sensitivity of $100 \gamma$, and the susceptibility detector has a sensitivity of $100 \times 10^{-6} \mathrm{cgs}$ units.

In 1978, this device made measurements in the Kolskaya Superdeep Well C1-3 (SD-3), where it reached 8000 meters at temperatures of about $130^{\circ} \mathrm{C}$. The magnetic field in this hole showed considerable variation at 


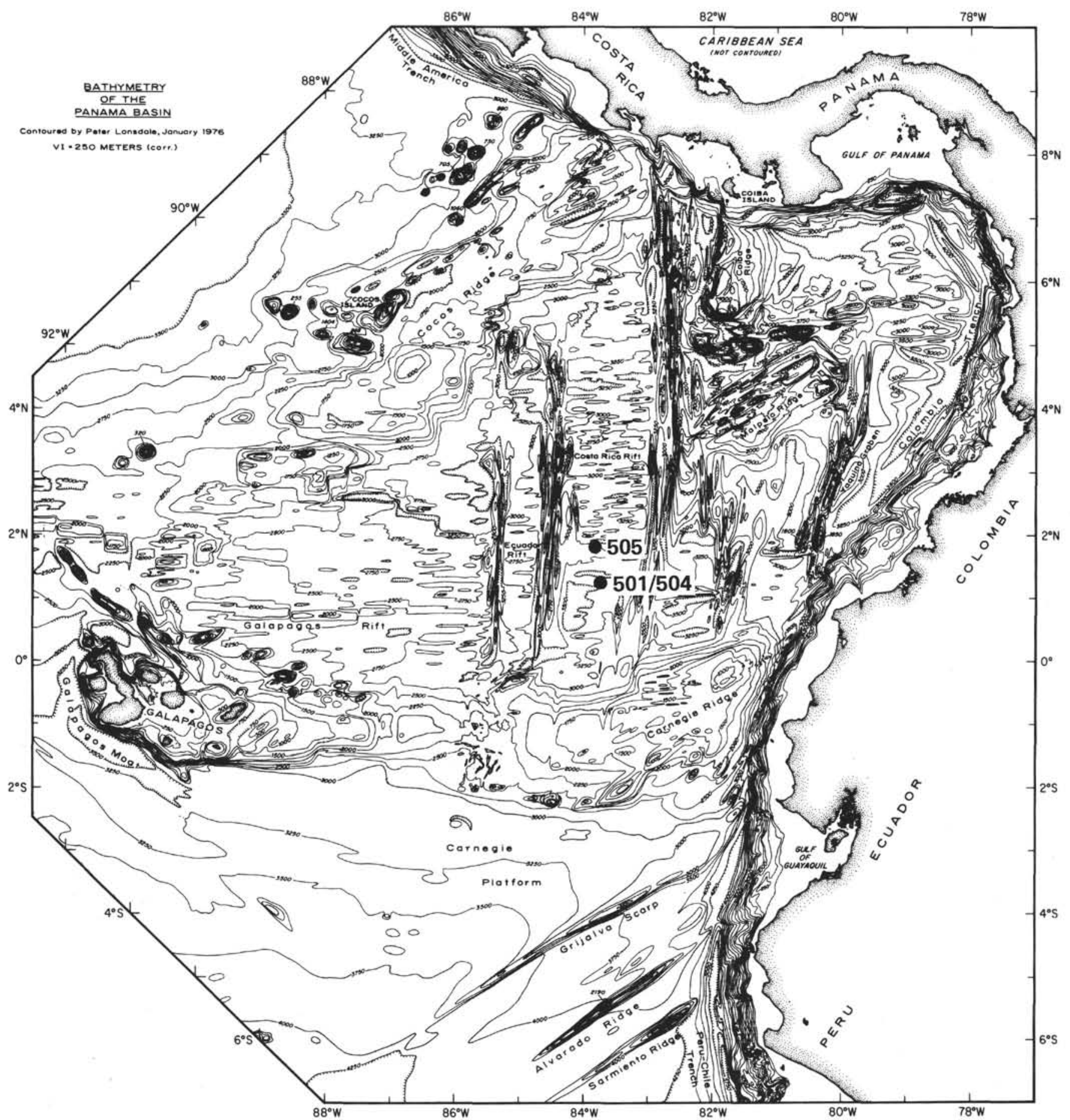

Figure 1. Location of Sites 501, 504, and 505 near the Costa Rica Rift in the Panama Basin. Bathymetry from Lonsdale and Klitgord (1978). Contour interval is $250 \mathrm{~m}$.

even the greatest depths. These measurements proved the scientific value of deep downhole magnetic surveying.

\section{INTERPRETATION OF RESULTS}

This section discusses the theoretical aspects of the interpretation of results from the downhole magnetometer as deployed in the ocean crust on Legs 68 and 69. More background and further elaboration can be found in Ponomarev and Bakhvalov (1969).
Consider the intensity of the magnetic field inside a magnetic body confined within a second-order surface. If $T_{i}$ is the total intensity of the field inside the body, $T_{0}$ the magnetizing field, tensor of magnetization $J$ the intensity of magnetization of the rock, and $N$ a factor varying from 0 to about $4 \pi$ depending on the geometry of the magnetized body, then

$$
\vec{T}_{i}=\vec{T}_{0}-\overrightarrow{N J} .
$$




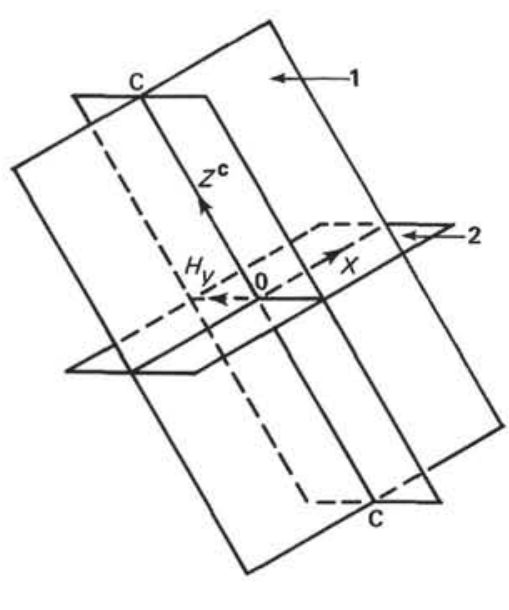

$$
\begin{aligned}
\vec{X} & =\vec{H} \cos A \cos \varphi-\vec{Z} \sin \varphi \\
\vec{H} & =\vec{H} \sin A \\
\vec{Z}^{\mathrm{c}} & =\vec{Z} \cos \varphi+\vec{H} \cos A \sin \varphi \\
\varphi= & \text { the angle of the hole } \\
& \text { inclination from the vertical }
\end{aligned}
$$

Figure 2. Schematic diagram illustrating alternative methods of measuring magnetic fields using downhole magnetometers. One method (left) is to allow the inclination of the hole and gravity to define a horizontal axis $X$ within the instrument and then measure the components of the magnetic field $\mathrm{C}$ in alignment with it. The other (which was used during Legs 68 and 69) measures the magnetic field $C$ in three vectoral components, allowing the vertical component $\vec{Z}$ to be measured directly by aligning the instrument using gravity.
Usually the anomalous component of the internal field $\left(T_{\mathrm{a}}\right)$ is of more interest than the total field, so that, subtracting $T_{0}$ from each side, Equation (1) becomes

$$
\vec{T}_{\mathrm{a}}=-\overrightarrow{N J} .
$$

The internal anomalous field will thus have a direction opposite to that of the magnetizing field and an amplitude for a given geometry proportional to the intensity of magnetization.

Within a basaltic section, the intensity of magnetization $J$ will be made up of two principal components: the remanent magnetization $\left(\vec{J}_{\mathrm{r}}\right)$ and the induced magnetization $\left(\vec{J}_{\mathrm{n}}\right)$, so that

$$
T_{\mathrm{a}}=-N J=-N\left(J_{\mathrm{r}}+J_{\mathrm{n}}\right) .
$$

The intensity of induced magnetization in rocks in which magnetic susceptibility $(K)$ is less than $10^{3} \mathrm{cgs}$ units can be taken as

$$
\vec{J}_{\mathrm{n}}=\overrightarrow{K T}_{0},
$$

so that

$$
\vec{T}_{\mathrm{a}}=-{\overrightarrow{N\left(\vec{J}_{\mathrm{r}}\right.}} \overrightarrow{\left.K T_{0}\right)} .
$$

$N$ may be determined from the form of the magnetic body with the help of the external surface anomaly, but it is usually taken as $2 \pi$. This assumption and measurements of the anomalous field, magnetic susceptibil-

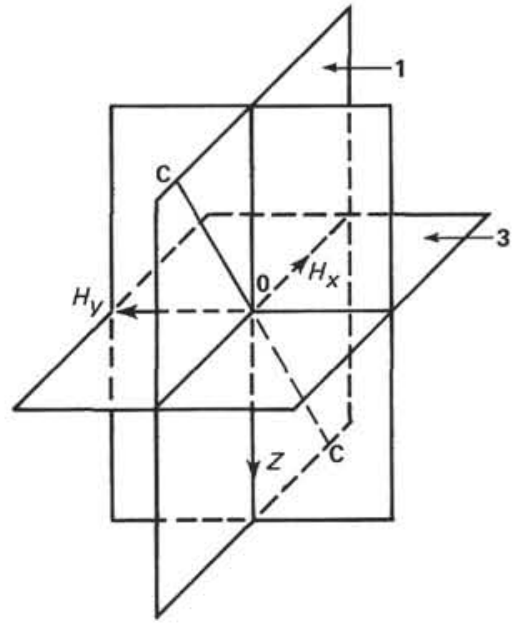

$$
\begin{aligned}
& \vec{H}_{x}=\vec{H} \cos A \\
& \vec{H}_{y}=\vec{H} \sin A \\
& \vec{Z}=\vec{Z}
\end{aligned}
$$

ity, and the local magnetizing field enable $J_{\mathrm{r}}$ to be calculated.

A convenient formulation considers the vertical component of the field only, which can be measured even in boreholes too near the vertical for stable measurements of the horizontal components to be made. Here a ratio $Q_{z}$ is calculated, which is analogous to the Königsberger ratio in its dependence on the relative importance of remanent and induced magnetization but is related to the intensity of the anomalous field rather than to the intensity of magnetization. $Q_{z}$ is defined by the equation

$$
Q_{z}=\frac{\vec{Z}_{\mathrm{a}}-\vec{Z}_{\mathrm{n}}}{\vec{Z}_{\mathrm{n}}},
$$

where $\vec{Z}_{\mathrm{a}}$ is the measured anomalous vertical field and $\bar{Z}_{\mathrm{n}}$ is the induced vertical field, calculated from the equation $\vec{Z}_{\mathrm{n}}=-N J_{\mathrm{nz}}$. Then

$$
Q_{z}=\frac{\vec{Z}_{\mathrm{a}}+\overrightarrow{N J}_{\mathrm{nz}}}{-N J_{\mathrm{nz}}}
$$

where $J_{\mathrm{nz}}$ is the vertical component of the induced magnetization. Since the geometry of the system is usually not known, it is convenient to substitute into this equation the maximum value of $N J_{\mathrm{n}}$ (which will result in the least value of $Q_{z}$ ):

$$
\begin{aligned}
N J_{\mathrm{n}}(\max ) & =\frac{4 \pi K}{(1+4 \pi K)} . \\
& \simeq 4 \pi K \cdot Z_{0}
\end{aligned}
$$


for the values of $K$ encountered here, where $\vec{Z}_{0}$ is the local vertical component of the magnetizing field.

The minimum value of $Q_{z}$ thus is

$$
Q_{z}(\min )=\frac{Z_{\mathrm{a}}+4 \pi K Z_{0}}{-4 \pi K Z_{0}},
$$

which is a convenient measure of the greatest contribution possible of induced relative to remanent magnetization.

From the two horizontal components $\vec{H}_{x}$ and $\vec{H}_{y}$ a value can be calculated for the total anomalous horizontal field $\vec{H}_{i}$, as well as its declination relative to the dip direction of the drill hole. If, in some sections of the hole, units occur in which $J$ is very low, as, for example, in pelagic sediment or in brecciated basalt, then $\vec{H}_{i}$ is close to $\vec{H}_{0}$, the local horizontal component of the normal magnetizing field. The declination of this field relative to the drill hole enables the dip direction of the drill hole to be evaluated. Once this has been established, the declination of the horizontal anomalous field $\left(\vec{H}_{\mathrm{a}}\right)$ at different levels in the hole can readily be calculated. This is particularly important at these low magnetic latitudes, since magnetic reversals will manifest themselves almost entirely through a change in the declination of the field rather than through its inclination.

Finally, by combining the vertical and horizontal components of the anomalous field, the magnitude and direction of the total anomalous field can be calculated, and this can be examined with a view to interpreting it in terms of the tectonic rotation of the rocks or secular variation in field direction.

\section{RESULTS}

\section{Hole 501}

Hole 501 was drilled on the top of a $300 \gamma$ positive anomaly (corresponding to reversely magnetized crust in the Costa Rica Rift) superimposed on a regional total field of about $36,000 \gamma$. At this magnetic latitude, this corresponds to a vertical component of about $11,500 \gamma$.

The magnetometer was used to log the interval between 3720 and $\mathbf{3 7 6 5}$ meters below the rig floor, across the sediment/basalt interface at $\mathbf{3 7 3 1}$ meters. The section logged is shown in Figure 3, where minicore intensities, inclinations, and susceptibilities are plotted, as well as the readout from the vertical component of the magnetometer. The two horizontal components were successfully logged at this hole, but an attempt to measure magnetic susceptibility within the hole was frustrated by inadequate sensitivity in the receiving equipment. Several successive runs showed that all the essential features of the field are reproduced from run to run.

The upper part of the section logged consists of pelagic siliceous nannofossil ooze of very low intensity of magnetization. The vertical anomalous field fluctuates within $\pm 300 \gamma$ of the mean of $300 \gamma$. The fluctuations of the curve are due to the ship's heave that causes field pickup oscillations, but these are not significant relative to the anomalies within the basalt. From the values of
$\vec{Z}, \vec{H}_{x}$, and $\vec{H}_{y}$ that were measured in this section of the hole, the direction of the dip of the hole could be determined as $311^{\circ}$.

At the sediment/basalt contact there is a narrow very strong negative anomaly, not exceeding 1 meter in width, with an amplitude of several thousand gammas. Similar anomalies are often caused by the presence of steel objects in the hole, but this is not believed to be the case here, and the anomaly is probably caused by the magnetic contrast between the highly magnetized basalts and the weakly magnetized sediments.

The basement can be divided into two layers on the basis of the vertical field log. The upper layer, between 3731 and 3751 meters below the rig floor, is characterized mainly by negative values of $\vec{Z}_{\mathrm{a}}$, corresponding to downward-directed anomalous magnetic field vectors. Only in a few places did $\vec{Z}_{\mathrm{a}}$ become positive. In this unit, $\vec{Z}_{\mathrm{a}}$ is as high as $-3000 \gamma$ and averages about $-1000 \gamma$. If the value given above for the vertical component of the local magnetizing field $\left(\vec{Z}_{0}=11,500 \gamma\right)$ and the mean value of $K$ measured on the minicores in this interval $(1600$ $\times 10^{-6}$ cgs units) are substituted into Equation (5), the minimum value of $Q_{z}$ is 3.7. The anomalous field must thus be primarily the result of remanent magnetization, as would be expected from the observed Königsberger ratios of the minicores (Furuta and Levi, this volume). The inclinations of the magnetic vectors measured for minicores in this upper layer are generally directed downwards, though subhorizontal, as would be expected at this low magnetic latitude, in general agreement with the observed negative values of $\overline{\bar{Z}}_{\mathrm{a}}$.

In the lower unit (3751-3765 m), the values of $\vec{Z}_{\mathrm{a}}$ are primarily positive, corresponding to an upward inclination of the anomalous field vectors. Within this unit, the anomalous field reaches about $5000 \gamma$ in places, with an average of $3000 \gamma$. Measurements on minicores give dominantly upward-directed magnetic vectors, corresponding to the positive values of $\vec{Z}_{\mathrm{a}}$, but magnetic susceptibility is 300 to $400 \times 10^{-6} \mathrm{cgs}$ units, four to five times as low as in the upper layer. The calculated minimum value of $Q_{z}$ thus reaches about 50, indicating an even greater dominance of remanent over induced magnetization in this interval.

Though the reversal in sign of $\vec{Z}_{\text {a }}$ might seem to indicate a polarity reversal in the basalts between the upper and lower units in the basement, consideration of the horizontal components shows that this cannot be the case. At these low magnetic latitudes a reversal would be most marked in the anomalous horizontal field $\left(\vec{H}_{\mathrm{a}}\right)$.

The $\dot{H}_{\mathrm{a}}$ field vectors are shown for seven different intervals in the basement of Hole 501 in Figure 4. Here they are plotted relative to the dip direction of the hole, which defines $\vec{H}_{x}$ and was determined to have an azimuth of $311^{\circ}$ from the log in the sediments. The $\vec{H}_{\mathrm{a}}$ field vectors in both the upper and lower magnetic unit are directed between south and southwest, showing that no reversal occurred. This is also shown by the plot of virtual geomagnetic pole positions for the upper and lower units (Fig. 5). The upper unit gives a virtual pole practically coincident with the present pole (Point 1 in Fig. 5, with coordinates $84^{\circ} \mathrm{N}, 24^{\circ} \mathrm{W}$ ), whereas the low- 


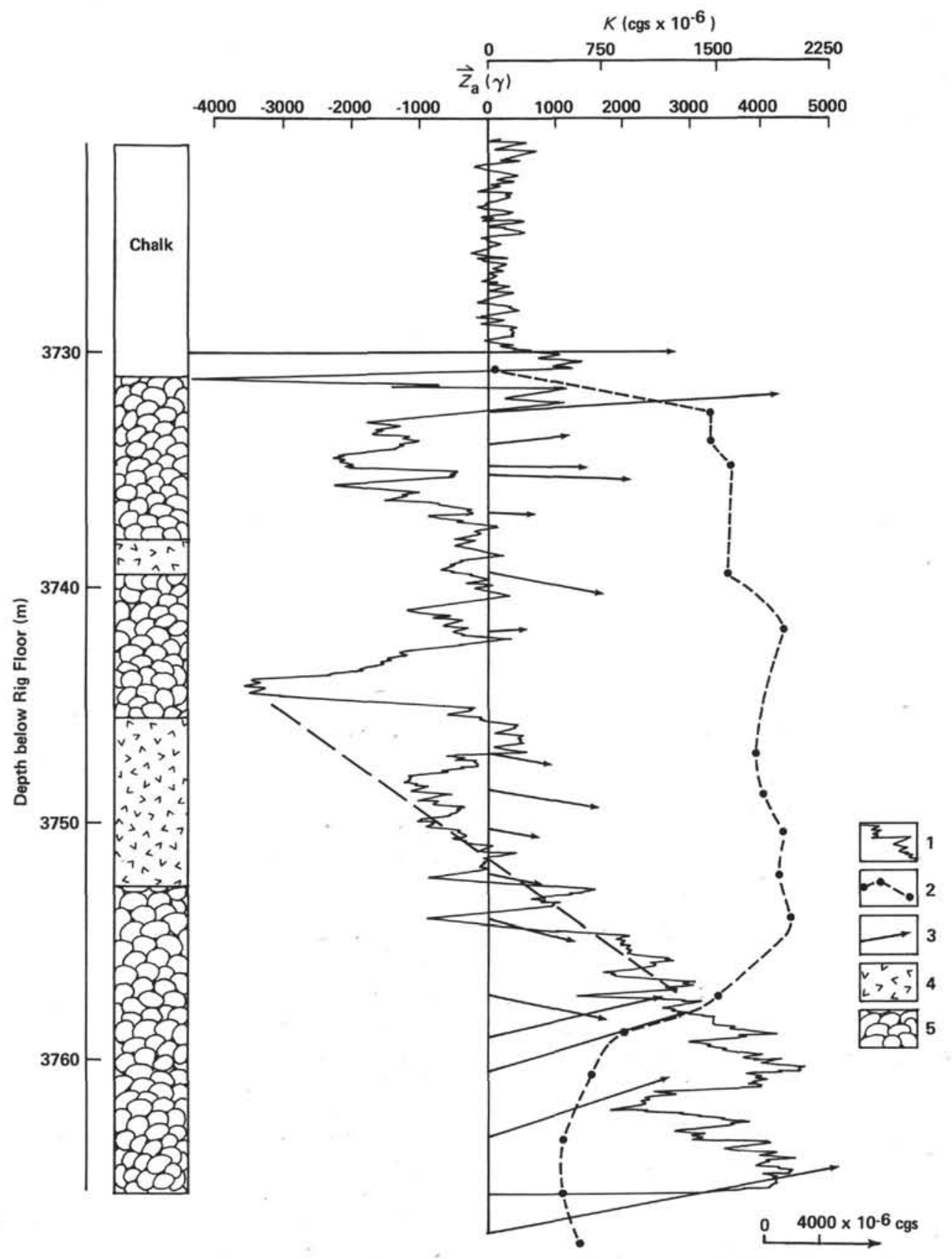

Figure 3. Magnetic measurements in Hole 501. 1-anomalous vertical component $\vec{Z}_{\mathrm{a}}$, measured using the downhole magnetometer. 2 -minicore magnetic susceptibility. 3 -minicore magnetization $\vec{T}$ vectors. 4-massive basalts. 5-pillowed basalts.

er unit gives a pole at a distinctly lower latitude (Point 2 in Fig. 5, with coordinates $36^{\circ} \mathrm{N}, 14^{\circ} \mathrm{E}$ ).

The crustal section here is thus seen to be uniformly reversely magnetized, as would be the polarity deduced from the surface magnetic anomaly. But whereas the anomalous field vector in the upper part of the basement is nearly parallel to, but reversed from, the present earth's field at the site, the anomalous field vector in the lower unit is rotated away from this direction. This rotation could be the result of either the secular variation of the Earth's field or the tectonic tilt of the lower unit. Both effects are likely to exist in the lower basalts in any such section, and it is not possible to distinguish one from the other with the information available.

\section{Hole 504B}

Hole 504B, which is about 500 meters away from Hole 501, was drilled during Leg 69 as a major re-entry site. The 250-meter sedimentary section was cased (lined) to a depth a few meters into basement so as to reduce the caving in of sediments into the hole. The basement was then drilled for 200 meters. During Leg 70 the hole was deepened by another 360 meters, and during Leg 83 it was deepened a further 490 meters, but only the upper 


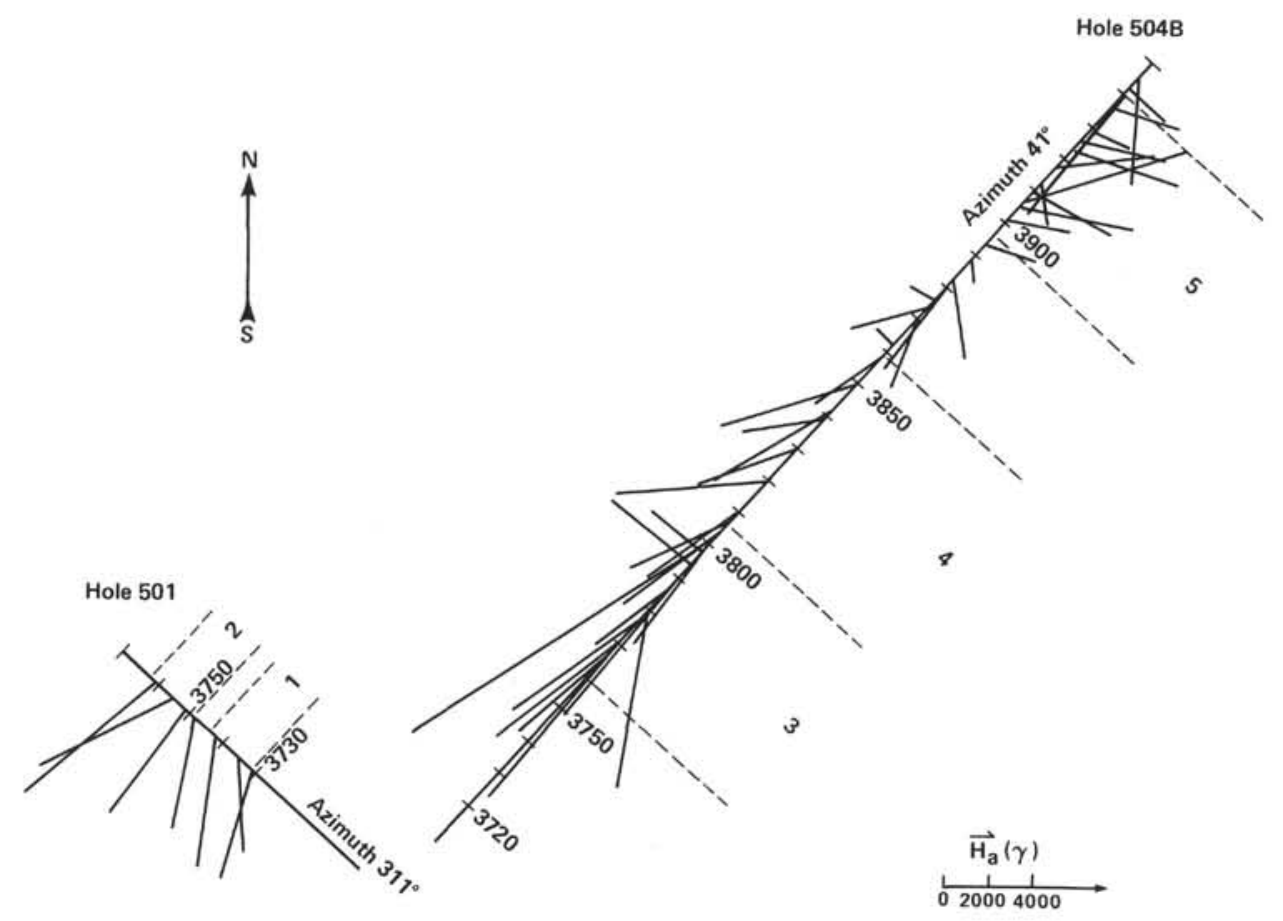

Figure 4. The projection of magnetic field $\vec{H}_{\mathrm{a}}$ anomalous horizontal component vectors on a horizontal plane. Depths are in meters below rig floor. The average interval values of magnetization were calculated for 1-to 5-meter intervals and were used to calculate the location of the virtual geomagnetic poles shown in Figure 5.

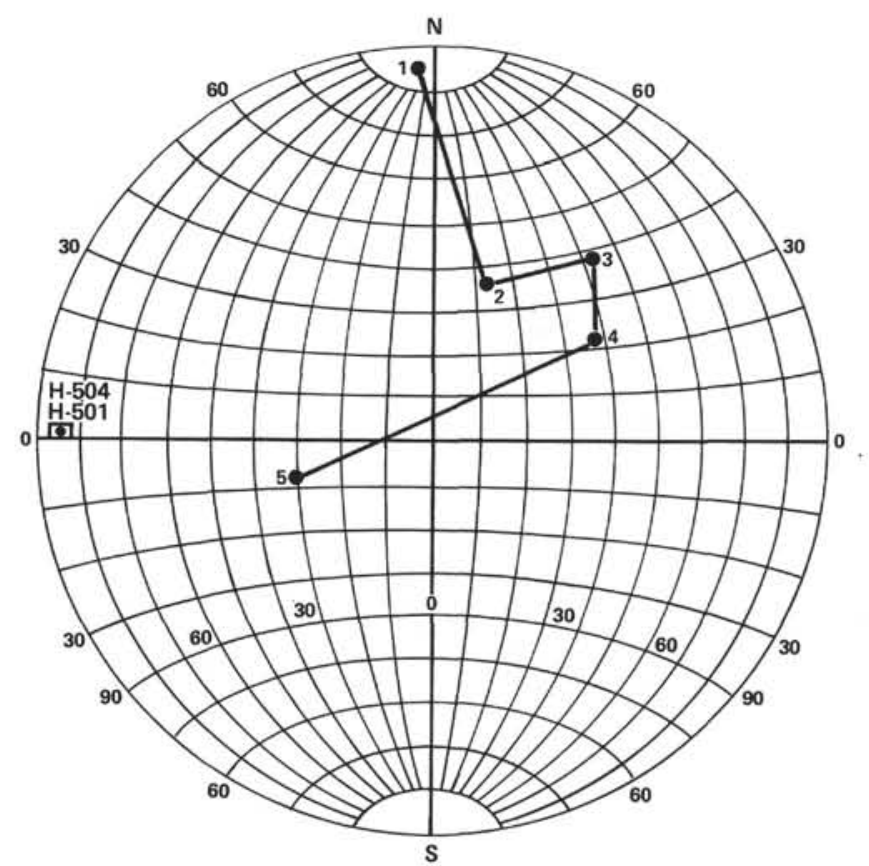

Figure 5. Five virtual geomagnetic poles calculated using downhole magnetometer results for the five separate intervals in Holes 501 (Points 1 and 2) and 504B (Points 3-5).

section of the basement (that between 3745 and $3945 \mathrm{~m}$ below the rig floor, or 280 to $480 \mathrm{~m}$ sub-bottom) was logged with the downhole magnetometer. Magnetic susceptibility and three components of the in-hole field $(\vec{Z}$, $\vec{H}_{x}$, and $\vec{H}_{y}$ ) were recorded separately. The determina- tion of magnetic susceptibility was affected by the high in-hole temperatures, however, and values measured on minicores were used in interpretation (Furuta and Levi, this volume).

Figure 6 shows the minicore magnetic measurements for the section drilled on Legs 69 and 70, together with the downhole magnetometer $\log$ of $\vec{Z}_{\mathrm{a}}$ for the upper 200 meters of the basement section.

The local total field measured by the ship's magnetometer is $32,825 \gamma$, including a positive anomaly of about $100 \gamma$. The vertical component of this field, calculated from that and the inclination, is estimated to be $12,400 \gamma$, and this value was used to calculate $\bar{Z}_{\mathrm{a}}$ from $\vec{Z}$. Values of $\vec{Z}_{\text {a }}$ are uniformly positive throughout the section, gradually decreasing from about $1000 \gamma$ at the top of the basement to about $600 \gamma$ at 200 meters into basement. Positive values of $\vec{Z}_{\mathrm{a}}$ correspond to upwarddirected magnetic vectors in the enclosing rocks, and Figure 6 shows that measurements on minicores support this conclusion. There is no unit in this hole that corresponds to the upper unit of Hole 501 , in which $\vec{Z}_{\mathrm{a}}$ is negative, and this is consistent with the differences in petrography (Site 501/504 chapter, this volume) and glass composition (Natland et al., this volume) in the upper parts of the basement in Holes 501 and 504B.

Using the minicore susceptibilities, $K$, shown in Figure 6, $Q_{z}$ decreases from about 15 near the top of the basement to about 4 at a depth of 200 meters. Over this interval, then, remanent magnetization is still dominant. However, in the region below 4200 meters, where minicore susceptibilities are higher and the intensity of remanent magnetization of the minicores is lower, it 


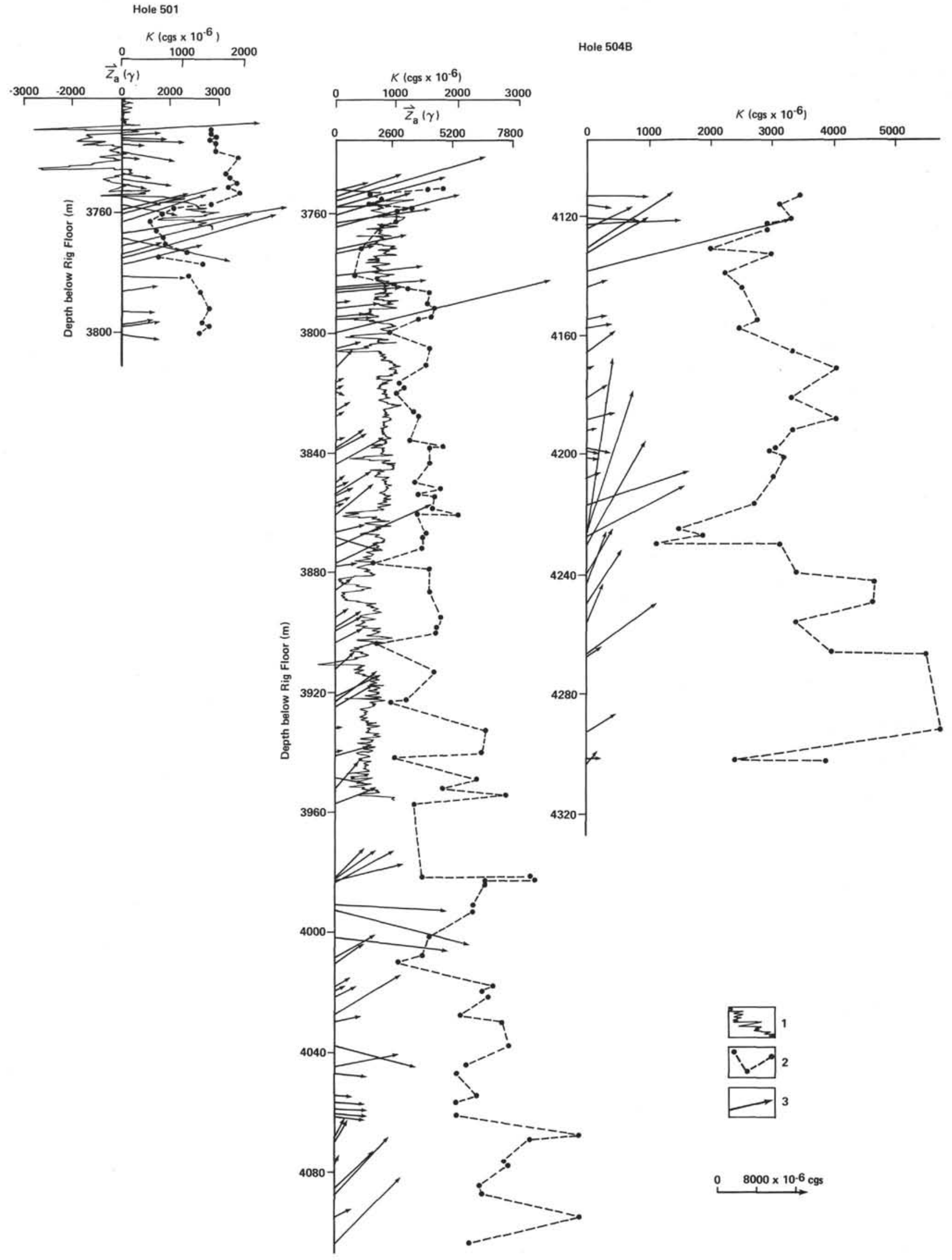

Figure 6. Magnetic measurements in Holes 501 and 504B. 1-3 as in Figure 3. 
seems likely that a log would show similar contributions to the anomalous field from remanent and induced magnetization.

In order to determine the azimuth of the $\vec{H}_{\mathrm{a}}$ component, the direction of the dip of the hole must be determined. The sedimentary section was cased, so it could not be used, as it had been in Hole 501. However, $\vec{Z}_{\mathrm{a}}$ dropped to very low values in several short sections of the basement $\log$. These short intervals of reduced $\vec{Z}_{\text {a }}$ are believed to be the result of brecciation, corresponding as they do to regions of relatively high porosity in the conventional downhole logs (Cann and Von Herzen, this volume). Two sections in particular, those from 3881 to 3883 meters and from 3886 to 3889 meters, gave total field vectors close in intensity and inclination to those of the local magnetizing field, and these gave concordant values for the direction of dip of the hole $\left(41^{\circ}\right)$. The directions of $\vec{H}_{\mathrm{a}}$ vectors for different horizons in the hole could be calculated relative to this azimuth, and the results are plotted in Figure 4.

Figure 4 shows that in the upper part of the basement, $\vec{H}_{\text {a }}$ vectors point generally southwest, in a direction similar to those in the shorter section of Hole 501. Below $\mathbf{3 8 8 0}$ meters, though, the $\vec{H}_{\mathrm{a}}$ vectors swing around to the southeast to east. This change of direction is clearly shown by the virtual geomagnetic poles in Figure 5 , where point $3\left(39^{\circ} \mathrm{N}, 43^{\circ} \mathrm{E}\right)$ corresponds to the uppermost interval from 3759 to 3806 meters, Point 4 $\left(21^{\circ} \mathrm{N}, 39^{\circ} \mathrm{E}\right)$ corresponds to the interval from 3806 to 3859 meters, and Point $5\left(7^{\circ} \mathrm{S}, 30^{\circ} \mathrm{W}\right)$ corresponds to the lowermost interval from 3886 to 3940 meters. The anomalous field vectors in the section above $3880 \mathrm{me}-$ ters correspond clearly to reversely magnetized rock, though there may have been some degree of tectonic rotation. The virtual geomagnetic poles from this section (Points 3 and 4 ) lie very close to those for the lower unit of Hole 501 (Point 2). As the $\vec{H}_{\mathrm{a}}$ vectors swing around to the east below $3880 \mathrm{~m}$, the anomalous field vectors can no longer be said to be completely reversed. The excursion seems rather large to be caused by secular variation alone, although some combination of this with tectonic rotation might be sufficient. Alternatively, this swing might be associated with a reversal of the Earth's field as the basalts were being erupted.

It is clearly highly desirable to log the lower section of the hole by downhole magnetometer. It would then be possible to examine whether this swing was part of a reversal. It would also be possible to investigate the part of the hole where minicore inclinations become very high (Fig. 6), presumably principally because of tectonic rotations at depth (Furuta and Levi, this volume), and where it seems likely that remanent and induced magnetization have equal importance. An investigation of all these effects could prove to be of great importance.

\section{Hole 505B}

Hole 505B was uncased, and here the lower part of the sediment section as well as the short basalt section could be logged. Unfortunately, the hole was too close to the vertical for the orientation of $\vec{H}_{x}$ and $\vec{H}_{y}$ to sta- bilize, so that only $\vec{Z}$ was usable. Figure 7 shows a plot of $\bar{Z}_{\mathrm{a}}$ and minicore measurements taken from Furuta and Levi (this volume). As in Hole 501, $\vec{Z}_{\mathrm{a}}$ is near zero in the weakly magnetized sediments, and it shows a peak (though not a large one) at the basalt contact. Within the basalt, the values of $\vec{Z}_{\mathrm{a}}$ are all positive, suggesting upward-directed magnetic vectors in the surrounding rocks, in agreement with the minicore measurements. The calculation of $Q_{z}$ gives values between 10 and 20, suggesting, as in the logged parts of the other holes, that remanent is dominant over induced magnetization.

\section{CONCLUDING REMARKS}

These first measurements of the three components of the Earth's magnetic field within the oceanic crust have

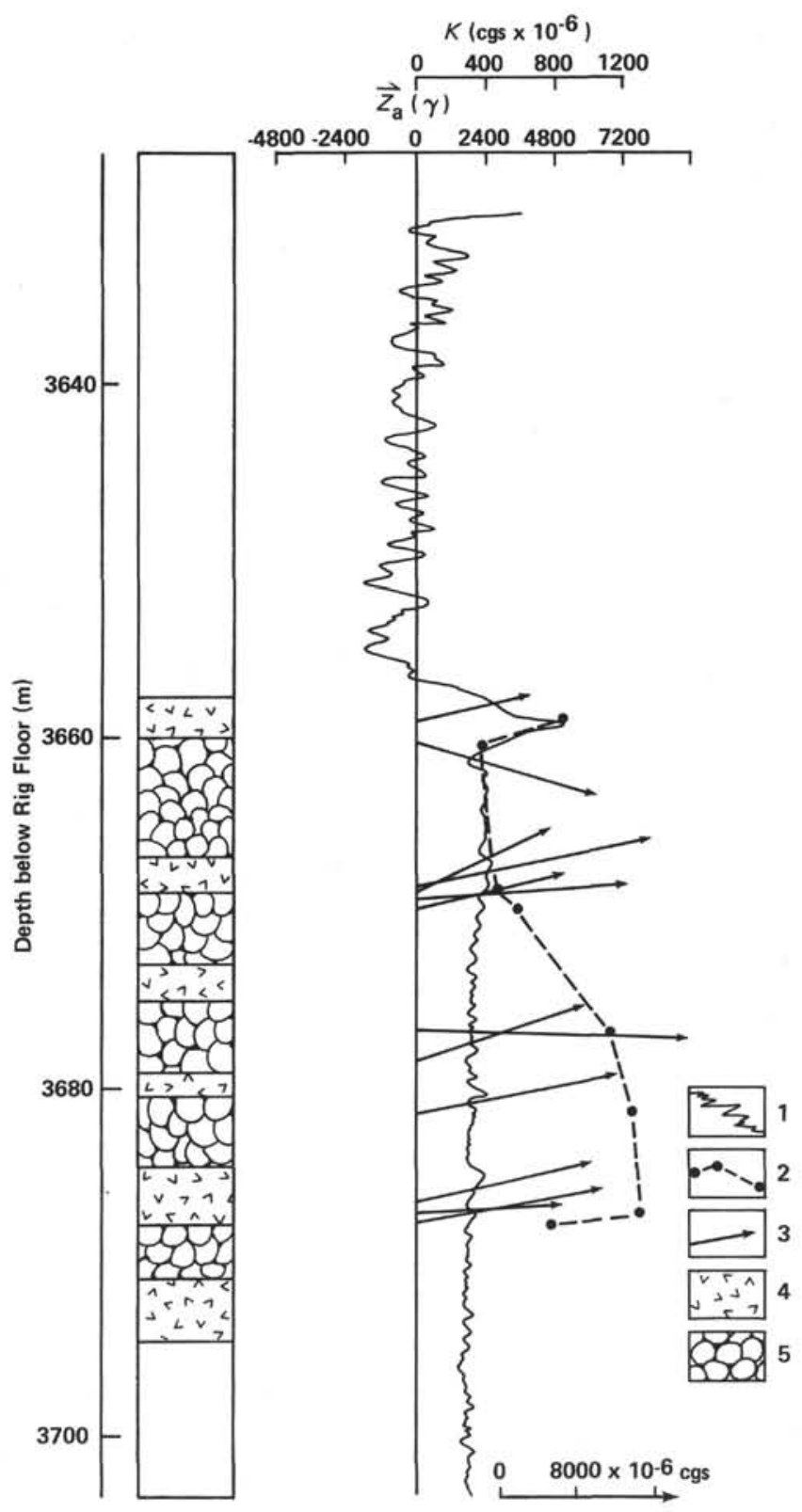

Figure 7. Magnetic measurements in Hole 505B. 1-5 as in Figure 3. 
contributed new information about the rocks of the ocean crust and have shown the potential for the use of this method in the future.

The results from downhole magnetometry are particularly important in low magnetic latitudes, where the inclinations of the magnetic vectors in the crust are nearly horizontal. In this case minicores, which carry inclination data only, provide only a small part of the necessary information. The horizontal components of magnetization, which alone can indicate whether a field reversal has occurred or not, can only be provided by downhole magnetometry. However, the ambiguity in interpretation between secular variation and tectonic rotation will always be a problem in either method.

If the full potential of downhole magnetometer measurements is to be realized, the effect of the heave of the vessel, which causes oscillations of $\pm 300 \gamma$ in the records, must be reduced. The magnetometer itself is capable of much greater resolution than that, and with some stabilization in the hole it would give much more detailed information.

With greater experience in operating the downhole magnetometer and in interpreting the results in combination with paleomagnetic measurements on minicores, the opportunity will exist for a better understanding of details of the magnetic structure of the ocean crust. This in turn will improve our understanding of the processes of construction and evolution in the ocean crust.

\section{ACKNOWLEDGMENTS}

The authors avail themselves of this opportunity to express their gratitude to the Deep Sea Drilling Project for the organization and arrangement of all the necessary facilities for carrying out this new type of geophysical survey during Legs 68 and 69 , and also to J. R. Cann and J. Natland for their assistance in preparing the manuscript. We are also grateful to Dr. N. Pertsev, with whom we discussed the results obtained in the course of the present study, and to Dr. N. A. Bogdanov for his initiative in the organization of our scientific investigations. H. P. Johnson kindly reviewed the manuscript.

\section{REFERENCES}

Harrison, C. G. A., and Watkins, N. D., 1978. Shallow inclinations of remanent magnetism in Deep Sea Drilling Project igneous cores: geomagnetic field behaviour or post-emplacement effects? J. Geophys. Res., 82:4869-4877.

Lonsdale, P., and Klitgord, K. D., 1978. Structure and tectonic history of the eastern Panama Basin. Geol. Soc. Am. Bull., 85: $1697-1712$.

Ponomarev, V. N., and Bakvalov, A. N., 1969. Borehole magnetic prospecting and magnetic logging. In Zabarovsk, A. I., and Nikitsk, V. E. (Eds.), Handbook of Geophysics (Vol. 6): Moscow (Nedra), 182-210. (In Russian) 